\title{
Volatile changes in cv. Verdeal Transmontana olive oil: From the drupe to the table, including storage
}

\author{
Ricardo Malheiro $^{\mathrm{a}, \mathrm{b}}$, Susana Casal ${ }^{\mathrm{b}}$, Nuno Rodrigues ${ }^{\mathrm{a}}$, Catherine M.G.C. Renard ${ }^{\mathrm{c}}$, \\ José Alberto Pereira, ${ }^{\mathrm{a}, *}$ \\ a Centro de Investigação de Montanha (CIMO), ESA, Instituto Politécnico de Bragança, Campus de Santa Apolónia, 5300-253 Bragança, Portugal \\ ${ }^{\mathrm{b}}$ REQUIMTE/LAQV/Laboratório de Bromatologia e Hidrologia, Faculdade de Farmácia, Universidade do Porto, Porto, Portugal \\ ' UMR408 SQPOV "Sécurité et Qualité des Produits d'Origine Végétale", INRA, Avignon University, F-84000 Avignon, France
}

\section{A R T I C L E I N F O}

\section{Keywords:}

Olea europaea

Aroma

Sensory

Extraction

Storage

\begin{abstract}
A B S T R A C T
This study focused on the volatile changes in cv. Verdeal Transmontana throughout the entire olive oil processing chain, from the drupe to olive oil storage up to 12 months, while correlating it with quality parameters and sensory quality.

During crushing and malaxation, the volatiles formed were mainly "green-leaf volatiles" (GLVs), namely $(E)$ 2-hexenal, hexanal, and 1-hexanol. Centrifugation and clarification steps increased the total volatile amounts to $130 \mathrm{mg} \mathrm{kg}^{-1}$. However, clarification also increased nonanal and (E)-2-decenal contents, two markers of oxidation, with a noticeable loss of phenolic compounds and oxidative stability. During storage, the total volatile amounts reduced drastically ( $94 \%$ at 12 months after extraction), together with the positive sensory attributes fruity, green, bitter, and pungent. Despite being classified as extra-virgin after one year of storage, peroxides and conjugated dienes were significantly higher while there was a reduction in antioxidant capacity as well as in phenolic compounds (less 50\%) and oxidative stability (57\%).

The present work allowed concluding that the extraction process modulates the volatile composition of olive oil, with a concentration of volatiles at the clarification step. During storage, volatiles are lost, mainly eight months after extraction, leading to the loss of important sensory attributes.
\end{abstract}

\section{Introduction}

Olive oil is recognized not only for the healthy properties ascribed to its high content in oleic acid and some minor components, but also for its unique sensory characteristics, absent in other vegetable oils. Volatiles are a group of compounds responsible for part of the sensory characteristics in olive oil, influencing its overall quality. Volatile types and amounts can be influenced by a series of variables: olive cultivar (Ridolfi, Terenziani, Patumi, \& Fontanazza, 2002), ripening stage (Kalua, Allen, Bedgood, \& Bishop, 2005), and geographical origin (Youssef et al., 2011), among others (age of the tree; agricultural practices; pedoclimatic conditions; incidence of pests and diseases) (Malheiro, Casal, Baptista, \& Pereira, 2015). Besides all the variables mentioned, the extraction process is one of the most influencing factors (Caporaso, 2016). During olive oil extraction, olives pass through a series of processing steps that activate various biochemical pathways which lead to the formation of volatiles, and each extraction step influences the final profile (Ranalli, Cabras, Iannucci, \& Contento, 2001).
For instance, starting from the crushing system, stone mills produce olive oils with higher abundance of volatiles responsible for the green and freshly cut grass, comparatively to hammer crushers (Veillet, Tomao, Bornard, Ruiz, \& Chemat, 2009). After crushing, malaxation allows the further development of volatiles, where time, temperature and oxygenation of the paste considerably influence the final profile (Gómez-Rico, Inarejos-García, Salvador, \& Fregapane, 2009; Servili et al., 2008). Longer malaxation time and higher temperature lead to the reduction of volatile compounds connoted with pleasant attributes, while increasing the presence of potential off-flavors derived from the conversion of fatty acids, amino acids and phenolic compounds (Angerosa, Mostallino, Basti, \& Vito, 2001).

The type of centrifugal decanter, of two or three phases, which allows the separation of the oil must from the pomace and olive mill wastewater, also influences the amounts and type of volatiles. Ranalli et al. (2001) observe higher total volatiles retention in olive oils extracted in two-phase extraction systems. Even the centrifuge drum speed affects the volatile profile, with higher fruity and green

\footnotetext{
* Corresponding author.

E-mail address: jpereira@ipb.pt (J.A. Pereira).
} 
sensations in three-phase decanters but only at higher speeds (Caponio, Summo, Paradiso, \& Pasqualone, 2014).

After centrifugation, olive oil is further cleaned through a clarification step, also called vertical centrifugation. This step is known to reduce volatiles by nearly $14 \%$ (Masella, Parenti, Spugnoli, \& Calamai, 2009) while increasing the six-carbon volatiles (C6) derived from oxidation of linoleic acid by $16 \%$ (hexanal, and 1-hexanol) and proportionally reducing those from oxidation of linolenic acid $((E)-2$-hexenal; (Z)-3-hexenol; and (E)-2-hexenol) (Masella et al., 2009). The same authors report that vertical centrifugation carried out with inert gas (argon) preserves the aromatic properties and composition of the oils extracted (Masella, Parenti, Spugnoli, \& Calamai, 2012). Olive oil filtration at an industrial-scale has a different impact according to the volatile. Many volatiles are unaffected; others double their concentration (2-methylbutanal. 6-methyl-5-hepten-2-one, and heptanol); and some others significantly decrease their concentration after filtration ( $(E, E)$-2-hexadienal, $(E)$-2-hexen-1-ol, and (Z)-2-penten-1-ol) (Sacchi, Caporaso, Paduano, \& Genovese, 2015).

In the final product, the olive oil, the volatile profile will continue to change during storage (Aparicio, Morales, \& Alonso, 1996), here with a strong influence of autoxidation reactions that lead to a great loss of volatiles and a consequent impairment of sensory properties, quality, composition and bioactive properties (Kalua, Bedgood, \& Prenzler, 2006). In fact, it has been demonstrated by Genovese, Caporaso and Sacchi (2015) that the volatile changes are noticed a few weeks after opening an olive oil bottle.

Globally, the available literature on different cultivars and processing conditions supports the undoubtable importance of each processing step to the final oil quality. However, a full step-by-step evaluation of the relative impact of each processing phase during the entire olive oil production chain, including the storage period, has never been performed. Therefore, the main objective of this work was to perform a thorough evaluation of the volatile fraction of a single cultivar, cv. Verdeal Transmontana (one of the most widespread olive cultivars in Trás-os-Montes region, northeast of Portugal) throughout the extraction process of olives and during olive oil storage, while tentatively establishing correlations with standard quality parameters, including sensory analysis, total phenols content, oxidative stability, and antioxidant activity of the oils. For this purpose, each step of the extraction process was studied for the volatile characterization (olives, crushed and malaxed olives pastes, olive must, and final olive oil). The bottled olive oil was further analyzed every 4 months, up to 12 months, to study the possible volatile fraction changes in the olive oil. To the authors' knowledge, this is the first study of this kind carried out in this cultivar. The results obtained may be important since the olive oils studied originate from a key olive cultivar from one of the most important producing regions in Portugal. Furthermore, this type of studies could lead to improvements in the extraction process for obtaining olive oils with unique sensory characteristics.

\section{Material and methods}

\subsection{Collection of samples}

For the present study, the cv. Verdeal Transmontana was selected. In the olive mill, samples from all the stages of the olive oil extraction process were recovered, with 5 samples (approx. $100 \mathrm{~g}$ or $125 \mathrm{~mL}$ ) at each of the following stages: olives in reception (maturation index 1-2, according to Hermoso et al., 1991); crushed olive paste in stone miller (crushing); malaxed olive paste for $1 \mathrm{~h}$ at $27^{\circ} \mathrm{C}$ (malaxation); centrifuged in a two-phase decanter (centrifugation); and final olive oil (clarification). Six hundred kilograms of olives were collected to extract the olive oil. The stone mill was composed of three frusto-conical stones, rotating at a speed of $15 \mathrm{rpm}$. The centrifuge decanter and the centrifugal separator were made by GEA (Düsseldorf, Germany). The centrifuge decanter (model_RC305) was operated at $4000 \mathrm{rpm}$ with water added at room temperature at a ratio of $20 \mathrm{Lh}^{-1}$. The centrifugal separator was operated at $6200 \mathrm{rpm}$. Every $17 \mathrm{~min}$, the decanter and centrifuge were automatically cleaned as pre-programmed. A total of 40 samples $(5 \times 5$ processing steps $+5 \times 3$ storage times) were collected.

\subsection{Reagents and standards}

The following reagents were used to determine the quality parameters, antioxidant activity and total phenols content of the olive oil: diethyl ether, chloroform, isooctane, ethyl acetate, hexane, methanol, and phenolphtalein were obtained from Fisher Chemical by Thermo Fisher Scientific (Geel, Belgium). Ethanol 96\%, glacial acetic acid, potassium iodide, starch, sodium thiosulphate, caffeic acid, FolinCiocalteau, and sodium carbonate were obtained from Panreac (Barcelona, Spain). 2,2-Diphenyl-1-picrylhydrazyl was obtained from Sigma-Aldrich (St. Louis, USA).

The following standards were used for the volatile profile determination: hexanal, heptanal, decanal, (Z)-3-hexen-1-ol, (Z)-3-hexenyl acetate, hexyl 2-methylbutanoate, undecane, dodecane, tetradecane, 6methyl-5-hepten-2-one, and 4-methyl-2-pentanol, all obtained from Sigma-Aldrich (St. Louis, USA). (E)-2-hexenal, octanal, phenylacetaldehyde, nonanal, (E)-2-decenal, hexanol, and hexyl acetate were obtained from Acros Organics by Thermo Fisher Scientific (Geel, Belgium). D-limonene was obtained from Fisher Chemical by Thermo Fisher Scientific (Geel, Belgium).

\subsection{Quality parameters evaluated}

In the olive fruits, crushed and malaxed olive pastes, the volatile profiles were determined within the first $24 \mathrm{~h}$ after sample collection. In the centrifuged and cleaned olive oils, the volatile profile was determined 3 days after extraction, with the oils kept at room temperature in the dark until analysis.

The sensory analysis of the cleaned olive oil was determined 6 and 12 months after extraction to assess possible changes during storage. The analysis was performed according to the methodology described in the standards of International Olive Council (IOC), namely COI/T.30/ Doc. No. 17 (2014). A team of four trained panel members assessed the olive oil samples. The number of trained panelists was decided according to the amount of olive oil available and bearing in mind the amounts needed to perform the remaining chemical parameters. Each trained panelist evaluated olfactory, gustatory-retronasal, and final olfactory-gustatory sensations, in this order, all accounting for a total of 100 points. The following attributes were evaluated in the olfactory sensations (maximum of 35 points): olive fruitiness (0-7); other fruits (0-3); green (grass/leaves) (0-2); other positive sensations (0-3); and harmony (0-20). For the gustatory-retronasal sensations, the following parameters were assessed (maximum of 45 points): olive fruitiness (0-10); sweet (0-4); bitter (0-3); pungent (0-3); green (grass/leaves) (0-2); other positive sensations (0-3); and harmony (0-20). For the olfactory-gustatory sensations (maximum of 20 points), two parameters were assessed: complexity (0-10) and persistence (0-10).

Standard quality parameters (free acidity, peroxide value, $\mathrm{K}_{232}$, $\mathrm{K}_{270}$, and $\Delta \mathrm{K}$ ), were all determined according to the Europea Union standard methods (Annexes II and IX in European Community Regulation EEC/2568/91 of 11th July).

The oxidative stability, antioxidant activity (DPPH) and total phenols content were determined in the centrifuged and cleaned olive oils, as well as in the cleaned olive oil 12 months after extraction. For each determination the methodologies used were those described by Sousa et al. (2015). Briefly, the oxidative stability was measured in a Rancimat 743 apparatus (Metrohm $\mathrm{CH}$, Switzerland), using $3 \mathrm{~g}$ of olive oil heated at $120 \pm 1.6^{\circ} \mathrm{C}$ in which air was incorporated (filtered, cleaned, and dried) at a rate of $20 \mathrm{~L} / \mathrm{h}$. The resulting volatile compounds were collected in water, and the increasing water conductivity was continuously measured. The time taken to reach the conductivity 
Table 1

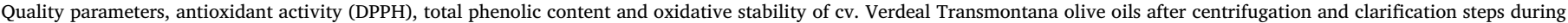
extraction and after one year of storage $\left(\mathrm{T}_{12}\right)$ at room temperature.

\begin{tabular}{|c|c|c|c|c|}
\hline Parameter & Centrifugation & Clarification $\left(\mathrm{T}_{0}\right)$ & $\mathrm{T}_{12}$ & $P$-value \\
\hline Free acidity (\%) & $0.35 \pm 0.05 \mathrm{a}$ & $0.33 \pm 0.05 \mathrm{a}$ & $0.35 \pm 0.03 \mathrm{a}$ & $.384^{(1)}$ \\
\hline Peroxide value (meq. $\mathrm{O}_{2} \mathrm{~kg}^{-1}$ ) & $1.3 \pm 0.6 \mathrm{a}$ & $1.5 \pm 0.3 \mathrm{a}$ & $9.2 \pm 0.9 \mathrm{~b}$ & $<.001^{(2)}$ \\
\hline $\mathrm{K}_{232}$ & $1.13 \pm 0.15 \mathrm{a}$ & $1.26 \pm 0.15 \mathrm{a}$ & $2.17 \pm 0.07 \mathrm{~b}$ & $<.001^{(1)}$ \\
\hline $\mathrm{K}_{270}$ & $0.19 \pm 0.03 \mathrm{~b}$ & $0.16 \pm 0.03 \mathrm{~b}$ & $0.10 \pm 0.01 \mathrm{a}$ & $<.001^{(2)}$ \\
\hline$\Delta \mathrm{K}$ & $-0.01 \pm 0.00 \mathrm{~b}$ & $-0.01 \pm 0.00 \mathrm{~b}$ & $-0.001 \pm 0.001 \mathrm{a}$ & $<.001^{(2)}$ \\
\hline DPPH (\%) & $44.9 \pm 1.3 \mathrm{~b}$ & $46.1 \pm 1.6 \mathrm{~b}$ & $37.2 \pm 2.6 \mathrm{a}$ & $<.001^{(2)}$ \\
\hline Total phenols (mg CAE kg ${ }^{-1}$ ) & $151 \pm 23 c$ & $130 \pm 20 \mathrm{~b}$ & $65 \pm 8 a$ & $<.001^{(2)}$ \\
\hline Oxidative stability & $20.3 \pm 0.7 c$ & $18.0 \pm 1.1 \mathrm{~b}$ & $7.7 \pm 0.9 \mathrm{a}$ & $<.001^{(1)}$ \\
\hline
\end{tabular}

${ }^{\mathrm{a}-\mathrm{c}}$ In the same line mean values with different letters differ significantly $(P<.05)$.

${ }^{1} P>.05$, by means of Levene test. $P$ values are those from one-way ANOVA analysis. Means were compared by Tukey's test, since equal variances could be assumed.

${ }^{2} P<.05$, by means of Levene test. $P$ values are those from one-way Welch ANOVA analysis. Means were compared by Dunnett T3's test, since equal variances could not be assumed.

inflection was recorded.

In the antioxidant activity, $1 \mathrm{~g}$ of olive oil was diluted in ethyl acetate $\left(100 \mathrm{~g} \mathrm{~L}^{-1}\right)$ and mixed with a DPPH solution with a concentration of $1 \times 10^{-4} \mathrm{M}$ in ethyl acetate. The mixture was then homogenized, kept in the dark for $30 \mathrm{~min}$ for reaction, and the absorbance was registered at $\lambda=515 \mathrm{~nm}$ against a blank solution.

For total phenols content, $2.5 \mathrm{~g}$ of olive oil were diluted with nhexane $(1: 1 \mathrm{w} / \mathrm{v})$, and extracted with $2.5 \mathrm{~mL}$ methanol/water (80:20; $\mathrm{v} / \mathrm{v}$ ) three times, with the mixture being centrifuged during $5 \mathrm{~min}$ at $5000 \mathrm{rpm}$. From the combined extract, $1 \mathrm{~mL}$ was added with the same amount of Folin-Ciocalteau reagent and $\mathrm{Na}_{2} \mathrm{CO}_{3}(7.5 \%)$, to which $7 \mathrm{~mL}$ of purified water were added. After homogenization, the mixture was stored overnight (12-16h) and a spectrophotometric analysis was performed at $\lambda=765 \mathrm{~nm}$. For quantification purposes, a calibration curve of caffeic acid was performed in concentration range $0.04-0.18 \mathrm{mg} / \mathrm{mL}$. The total phenols content was expressed as $\mathrm{mg}$ of caffeic acid equivalents per $\mathrm{kg}$ of olive oil ( $\mathrm{mg} \mathrm{CAE} \mathrm{kg}{ }^{-1}$ ).

\subsection{Volatile characterization}

The volatile profile of olives, crushed and malaxed olive pastes, centrifuged and cleaned olives oils, as well as cleaned olive oil at 4, 8 and 12 months after extraction was carried out through HS-SPME (headspace solid phase microextraction) and GC/MS (gas chromatography with mass spectrometry detector) according to the methodology described by Malheiro et al. (2017). Briefly, approximately $3 \mathrm{~g}$ of whole fruits, $5 \mathrm{~g}$ of crushed and malaxed olive paste, and $3 \mathrm{~g}$ of olive oil were used for the volatile characterization. All analyses were carried out in $50 \mathrm{~mL}$ glass vials, spiked with an accurate concentration of internal standard (4-methyl-2-pentanol) and volatiles adsorbed to an SPME fiber coated with divinylbenzene/carbonex/polydimethylsiloxane (DVB/ CAR/PDMS 50/30 $\mu \mathrm{m}$ ) (Supelco, Bellefonte, USA). The sampling conditions were determined based on a conjunction of the methodologies presented by Malheiro et al. (2017) and Peres et al. (2013). The samples were conditioned for $5 \mathrm{~min}$ at $30^{\circ} \mathrm{C}$ for an incisive release of the volatile compounds. After this period, the SPME fiber was exposed during $30 \mathrm{~min}$, at the same temperature, for the compounds adsorption from the headspace. Control samples (empty vials with internal standard) analyses were carried out regularly.

The volatile compounds were eluted from the fiber by thermal desorption for $1 \mathrm{~min}$ in the injection port of the chromatograph system $\left(220^{\circ} \mathrm{C}\right)$. The fiber was maintained for another $10 \mathrm{~min}$ in the injector port for cleaning and conditioning for further analyses. The gas chromatographer used was a Shimadzu GC-2010 Plus equipped with a mass spectrometer Shimadzu GC/MS-QP2010 SE detector. A TRB-5MS (30 $\mathrm{m} \times 0.25 \mathrm{~mm} \times 0.25 \mu \mathrm{m}$ ) column (Teknokroma, Spain) was used. The injector was set at $220^{\circ} \mathrm{C}$ and the manual injections were made in splitless mode, with helium (Praxair, Portugal) at a linear velocity of $30 \mathrm{~cm} / \mathrm{s}$ and a total flow of $24.4 \mathrm{~mL} / \mathrm{min}$ as mobile phase. The oven temperatures were the following: $40{ }^{\circ} \mathrm{C}(1 \mathrm{~min}) ; 2{ }^{\circ} \mathrm{C} / \mathrm{min}$ until $220^{\circ} \mathrm{C}$ (30 min). The ionization source was maintained at $250{ }^{\circ} \mathrm{C}$ with ionization energy of $70 \mathrm{eV}$, and with an ionization current of $0.1 \mathrm{kV}$. All mass spectra were acquired by electron ionization in the $m / z 35-500$ range. The full scan MS spectra fragments were compared with those obtained from a database (NIST 11) and with those of commercial standards acquired from diverse producers. For qualitative purposes, the areas of the chromatographic peaks were determined by integrating the reconstructed chromatogram from the full scan chromatogram using the ion base $(\mathrm{m} / \mathrm{z}$ intensity $100 \%)$ for each compound. For semi-quantification purposes, volatile amounts were calculated by the ratio of each individual base ion peak area to the area of the internal standard base ion peak area and converted to mass equivalents on the basis on the internal standard mass added.

\subsection{Statistical analysis}

\subsubsection{Analysis of variance}

An analysis of variance (ANOVA) with Type III sums of squares was performed using the GLM (General Linear Model procedure) of the SPSS software, version 22.0 (IBM Corporation, New York, U.S.A.). The fulfillment of the ANOVA requirements, namely the normal distribution of the residuals and the homogeneity of variance, were evaluated by means of the Kolmogorov-Smirnov with Lilliefors correction (if $\mathrm{n}>50$ ) or Shapiro-Wilk's test (if $\mathrm{n}<50$ ) and Levene's test, respectively. All the dependent variables were analyzed using a one-way ANOVA with or without Welch correction, depending on whether the requirement of the homogeneity of variances was fulfilled or not. If a statistical significant effect was found, means were compared using Tukey's significant difference multiple comparison test or Dunnett T3 test also depending on whether equal variances could be assumed or not. All statistical tests were performed at a 5\% significance level.

\subsubsection{Principal component analysis}

Principal components analysis (PCA) was applied for reducing the number of variables in the volatiles observed during the extraction process of olive oil from cv. Verdeal Transmontana and the changes in the volatile profile until the first year after extraction of the olive oil from the same cultivar. PCA was performed by using SPSS software, version 22.0 (IBM Corporation, New York, U.S.A.).

\subsubsection{Linear discriminant analysis (LDA)}

A linear discriminant analysis (LDA) was used as a supervised learning technique to classify the olive oils from cv. Verdeal Transmontana during storage according to their volatile profile (17 variables overall). A stepwise technique, using the Wilk's lambda method with the usual probabilities of F (3.84 to enter and 2.71 to remove), was applied for variable selection. This procedure uses a combination of forward selection and backward elimination procedures 
Table 2

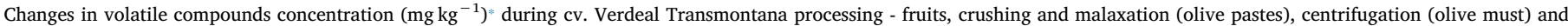
clarification (olive oil).

\begin{tabular}{|c|c|c|c|c|c|c|c|c|c|c|c|}
\hline $\mathrm{N}^{\circ}$ & Compound & $\mathrm{LRI}^{\mathrm{A}}$ & LRI Lit ${ }^{\mathrm{B}}$ & $\mathrm{QI}^{\mathrm{C}}$ & $\mathrm{ID}^{\mathrm{D}}$ & Fruits (mg kg ${ }^{-1}$ ) & Crushing ( $\mathrm{mg} \mathrm{kg}^{-1}$ ) & Malaxation ( $\mathrm{mg} \mathrm{kg}^{-1}$ ) & $\begin{array}{l}\text { Centrifugation } \\
\left(\mathrm{mg} \mathrm{kg}^{-1}\right)\end{array}$ & $\begin{array}{l}\text { Clarification }\left(\mathrm{T}_{0}\right) \\
\left(\mathrm{mg} \mathrm{kg}^{-1}\right)\end{array}$ & $P$-value \\
\hline \multicolumn{12}{|c|}{ Aldehydes } \\
\hline 1 & Hexanal & 797 & 801 & 44 & S/MS & - & $0.63 \pm 0.14 \mathrm{a}$ & $0.49 \pm 0.07 \mathrm{a}$ & $5.84 \pm 0.86 \mathrm{~b}$ & $8.37 \pm 0.56 \mathrm{c}$ & $<.001^{(1)}$ \\
\hline 2 & (E)-2-hexenal & 855 & 855 & 41 & S/MS & - & $6.95 \pm 1.30 \mathrm{a}$ & $6.91 \pm 1.29 \mathrm{a}$ & $65.5 \pm 15.0 \mathrm{~b}$ & $110 \pm 5.01 \mathrm{c}$ & $<.001^{(1)}$ \\
\hline 3 & Heptanal & 898 & 902 & 44 & S/MS & $0.005 \pm 0.002$ & - & - & - & - & - \\
\hline 4 & $(E, E)$-2,4-hexadienal & 906 & 909 & 81 & MS & - & $0.06 \pm 0.02 \mathrm{a}$ & $0.04 \pm 0.01 \mathrm{a}$ & $0.63 \pm 0.10 \mathrm{~b}$ & - & $<.001^{(1)}$ \\
\hline 5 & Octanal & 1001 & 998 & 43 & S/MS & $0.004 \pm 0.003$ & - & - & - & - & - \\
\hline 6 & Phenylacetaldehyde & 1041 & 1042 & 91 & S/MS & - & $0.01 \pm 0.00 \mathrm{a}$ & $0.01 \pm 0.00 \mathrm{a}$ & - & - & $.782^{(2)}$ \\
\hline 7 & Nonanal & 1098 & 1100 & 41 & S/MS & $0.003 \pm 0.002 \mathrm{a}$ & $0.01 \pm 0.00 \mathrm{a}$ & $0.01 \pm 0.00 \mathrm{a}$ & $0.06 \pm 0.01 \mathrm{~b}$ & $0.51 \pm 0.05 \mathrm{c}$ & $<.001^{(1)}$ \\
\hline 8 & Decanal & 1204 & 1201 & 43 & S/MS & tr. & - & - & - & - & - \\
\hline 9 & (E)-2-decenal & 1260 & 1263 & 43 & S/MS & - & - & - & - & $0.17 \pm 0.05$ & - \\
\hline \multicolumn{2}{|c|}{$\Sigma$ aldehydes } & & & & & $0.011 \pm 0.007 \mathrm{a}$ & $7.65 \pm 1.39 \mathrm{~b}$ & $7.45 \pm 1.36 \mathrm{~b}$ & $72.1 \pm 15.9 \mathrm{c}$ & $119 \pm 5.3 \mathrm{~d}$ & $<.001^{(1)}$ \\
\hline \multicolumn{12}{|c|}{ Alcohols } \\
\hline 10 & (Z)-3-hexen-1-ol & 860 & 859 & 67 & S/MS & - & $0.02 \pm 0.01 \mathrm{a}$ & $0.01 \pm 0.01 \mathrm{a}$ & $0.18 \pm 0.07 \mathrm{~b}$ & $0.19 \pm 0.06 \mathrm{~b}$ & $<.001^{(1)}$ \\
\hline 11 & 1-Hexanol & 871 & 870 & 56 & S/MS & - & $0.35 \pm 0.05 \mathrm{a}$ & $0.33 \pm 0.08 \mathrm{a}$ & $2.29 \pm 0.31 \mathrm{~b}$ & $4.42 \pm 0.64 \mathrm{c}$ & $<.001^{(1)}$ \\
\hline 12 & Phenylethyl alcohol & 1108 & 1107 & 91 & MS & - & $0.003 \pm 0.001 \mathrm{a}$ & - & - & $0.16 \pm 0.03 \mathrm{~b}$ & $<.001^{(1)}$ \\
\hline \multicolumn{2}{|c|}{$\Sigma$ alcohols } & & & & & - & $0.37 \pm 0.05 \mathrm{a}$ & $0.35 \pm 0.08 \mathrm{a}$ & $2.47 \pm 0.29 b$ & $4.77 \pm 0.70 \mathrm{c}$ & $<.001^{(1)}$ \\
\hline \multicolumn{12}{|c|}{ Esters } \\
\hline 13 & (Z)-3-hexenyl acetate & 1007 & 1005 & 43 & S/MS & $0.004 \pm 0.001 \mathrm{a}$ & - & - & $1.08 \pm 0.47 \mathrm{~b}$ & $4.26 \pm 0.38 c$ & $<.001^{(1)}$ \\
\hline 14 & Hexyl acetate & 1012 & 1009 & 43 & S/MS & - & - & - & $0.05 \pm 0.01 \mathrm{a}$ & $0.32 \pm 0.04 \mathrm{~b}$ & $<.001^{(2)}$ \\
\hline 15 & $\begin{array}{l}\text { Hexyl-2- } \\
\text { methylbutanoate }\end{array}$ & 1237 & 1236 & 103 & S/MS & tr. & - & - & - & - & - \\
\hline \multicolumn{2}{|c|}{$\Sigma$ esters } & & & & & $0.004 \pm 0.001 \mathrm{a}$ & - & - & $1.15 \pm 0.51 \mathrm{~b}$ & $4.58 \pm 0.41 \mathrm{c}$ & $<.001^{(1)}$ \\
\hline \multicolumn{12}{|c|}{ Sesquiterpenes } \\
\hline 16 & $\alpha$-Cubebene & 1356 & 1358 & 161 & MS & - & - & - & $0.02 \pm 0.00 \mathrm{a}$ & $0.17 \pm 0.03 \mathrm{~b}$ & $<.001^{(1)}$ \\
\hline 17 & Copaene & 1373 & 1376 & 161 & MS & $0.002 \pm 0.000 \mathrm{a}$ & $0.004 \pm 0.001 \mathrm{~b}$ & $0.005 \pm 0.001 \mathrm{~b}$ & $0.07 \pm 0.01 \mathrm{c}$ & $0.55 \pm 0.11 \mathrm{~d}$ & $<.001^{(1)}$ \\
\hline 18 & (E)- $\alpha$-bergamotene & 1432 & 1434 & 119 & MS & - & - & - & $0.02 \pm 0.01 \mathrm{a}$ & $0.14 \pm 0.02 \mathrm{~b}$ & $<.001^{(1)}$ \\
\hline 19 & $(E, E)$ - $\alpha$-farnesene & 1504 & 1505 & 41 & MS & - & - & - & - & $0.33 \pm 0.08$ & - \\
\hline 20 & $\delta$-Cadinene & 1517 & 1523 & 161 & MS & - & - & - & - & $0.09 \pm 0.01$ & - \\
\hline \multicolumn{2}{|c|}{$\Sigma$ sesquiterpenes } & & & & & $0.002 \pm 0.000 \mathrm{a}$ & $0.004 \pm 0.001 \mathrm{~b}$ & $0.005 \pm 0.001 \mathrm{~b}$ & $0.11 \pm 0.01 \mathrm{c}$ & $1.28 \pm 0.19 \mathrm{~d}$ & $<.001^{(1)}$ \\
\hline \multicolumn{12}{|c|}{ Terpenes } \\
\hline 21 & $\rho$-Cymene & 1022 & 1024 & 119 & MS & $0.002 \pm 0.000$ & - & - & - & - & - \\
\hline 22 & D-limonene & 1028 & 1029 & 68 & S/MS & $0.007 \pm 0.002 \mathrm{a}$ & $0.01 \pm 0.00 \mathrm{a}$ & - & - & - & $.456^{(2)}$ \\
\hline 23 & $(E)$ - $\beta$-ocimene & 1051 & 1050 & 93 & MS & - & - & - & $0.03 \pm 0.00 \mathrm{a}$ & $0.29 \pm 0.03 \mathrm{~b}$ & $<.001^{(1)}$ \\
\hline 24 & $\gamma$-Terpinene & 1058 & 1059 & 93 & MS & $0.001 \pm 0.000$ & - & - & - & - & - \\
\hline \multicolumn{2}{|c|}{$\Sigma$ terpenes } & & & & & $0.010 \pm 0.002 \mathrm{a}$ & $0.01 \pm 0.00 \mathrm{a}$ & - & $0.03 \pm 0.00 \mathrm{~b}$ & $0.29 \pm 0.03 \mathrm{c}$ & $<.001^{(1)}$ \\
\hline \multicolumn{12}{|c|}{ Alkanes } \\
\hline 25 & Undecane & 1100 & 1100 & 57 & S/MS & $0.008 \pm 0.002 \mathrm{a}$ & $0.01 \pm 0.00 \mathrm{a}$ & $0.003 \pm 0.001 \mathrm{a}$ & $0.04 \pm 0.01 \mathrm{~b}$ & - & $<.001^{(1)}$ \\
\hline 26 & Dodecane & 1200 & 1200 & 57 & S/MS & $0.001 \pm 0.000$ & - & - & - & - & - \\
\hline 27 & Tetradecane & 1400 & 1400 & 57 & S/MS & tr. & - & - & - & - & - \\
\hline \multicolumn{2}{|c|}{$\Sigma$ alkanes } & & & & & $0.010 \pm 0.002 \mathrm{a}$ & $0.01 \pm 0.00 \mathrm{a}, \mathrm{b}$ & $0.003 \pm 0.001 \mathrm{~b}$ & $0.04 \pm 0.01 \mathrm{c}$ & - & $<.001^{(1)}$ \\
\hline \multicolumn{12}{|c|}{ Hydrocarbons } \\
\hline 28 & $\begin{array}{l}\text { 3-Ethyl-1,5-octadiene } \\
\text { (I) }\end{array}$ & 942 & - & 69 & MS & - & $0.01 \pm 0.00 \mathrm{a}$ & $0.01 \pm 0.00 \mathrm{a}$ & $0.14 \pm 0.02 \mathrm{~b}$ & - & $<.001^{(1)}$ \\
\hline 29 & $\begin{array}{l}\text { 3-Ethyl-1,5-octadiene } \\
\text { (II) }\end{array}$ & 949 & - & 69 & MS & - & $0.03 \pm 0.01 \mathrm{a}$ & $0.03 \pm 0.01 \mathrm{a}$ & $0.38 \pm 0.07 b$ & - & $<.001^{(1)}$ \\
\hline 30 & $\begin{array}{l}\text { 4,8-Dimethyl-1,7- } \\
\text { nonadiene }\end{array}$ & 997 & -1 & 41 & MS & - & $0.02 \pm 0.01 \mathrm{a}$ & $0.03 \pm 0.01 \mathrm{a}$ & $0.43 \pm 0.22 \mathrm{~b}$ & $0.80 \pm 0.17 \mathrm{c}$ & $<.001^{(1)}$ \\
\hline \multirow{2}{*}{\multicolumn{2}{|c|}{$\begin{array}{l}\Sigma \text { hydrocarbons } \\
\text { Total volatiles }\end{array}$}} & & & & & - & $0.06 \pm 0.02 \mathrm{a}$ & $0.06 \pm 0.02 \mathrm{a}$ & $0.94 \pm 0.30 \mathrm{~b}$ & $0.80 \pm 0.17 \mathrm{~b}$ & $<.001^{(1)}$ \\
\hline & & & & & & $0.037 \pm 0.008 \mathrm{a}$ & $8.09 \pm 1.39 \mathrm{~b}$ & $7.87 \pm 1.45 \mathrm{~b}$ & $76.8 \pm 16.8 \mathrm{c}$ & $130 \pm 5.50 \mathrm{~d}$ & $<.001^{(1)}$ \\
\hline
\end{tabular}

${ }^{\mathrm{a}-\mathrm{d}}$ In the same line mean values with different letters differ significantly $(P<.05)$.

* Values are from semi-quantification using 4-methyl-2-pentanol as internal standard.

${ }^{A}$ LRI - Linear retention index obtained.

${ }^{\text {в }}$ LRI Lit - Linear retention index reported in literature (Adams, 2007).

C Quantification ion.

${ }^{D}$ Identification method (S - identified with standard; MS - identified by comparing mass spectrum with database NIST 11 ); tr. - below $0.001 \mathrm{mg}$ kg ${ }^{-1}$.

${ }^{1} P<.05$, by means of Levene test. $P$ values are those from one-way Welch ANOVA analysis. Means were compared by Dunnett T3's test, since equal variances could not be assumed.

${ }^{2} P>.05$, by means of Levene test. $P$ values are those from one-way ANOVA analysis. Means were compared by Tukey's test.

where before selecting a new variable to be included, an assessment is made of whether all variables previously selected remain significant. With this approach, it is possible to identify the significant variables among all variables under study. In order to verify which canonical discriminant functions were significant, the Wilks' Lambda test was applied. In order to avoid overoptimistic data modulation, a leavingone-out cross-validation procedure was carried out to assess the model performance. Moreover, the sensibility and specificity of the discriminant model were computed from the number of individuals correctly predicted as belonging to an assigned group. Sensibility was calculated by dividing the number of samples of a specific group correctly classified by the total number of samples belonging to that specific group. Specificity was calculated by dividing the number of samples of a specific group classified as belonging to that group by the total number of samples of any group classified as belonging to that specific group. The LDA was performed by using the SPSS software, version 


\section{A - processing}

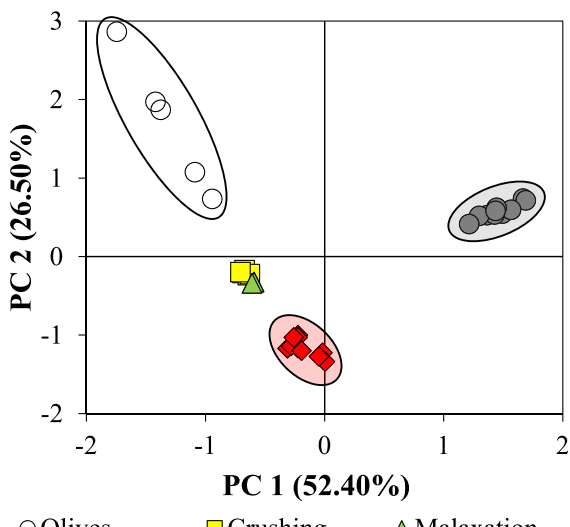

Olives $\quad \square$ Crushing

B - storage

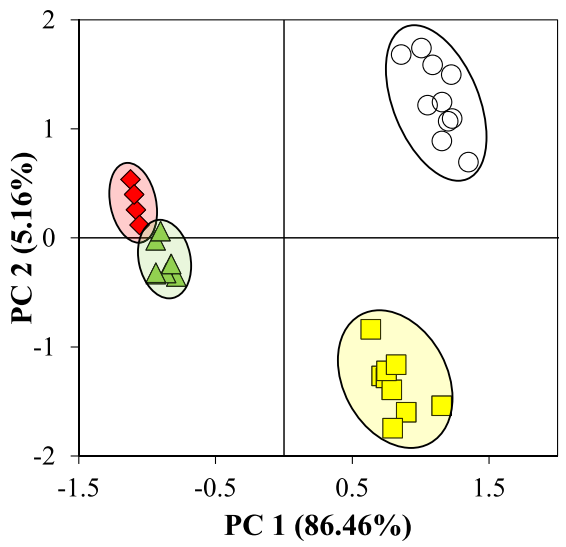

० $0 \quad \square \mathrm{T} 4 \quad \triangle \mathrm{T} 8 \quad \diamond \mathrm{T} 12$

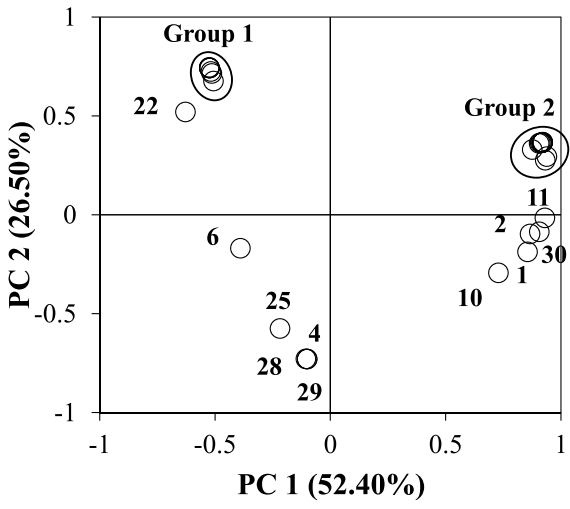

Fig. 1. Principal component analysis obtained from the volatile profile during the extraction process of $\mathrm{cv}$. Verdeal Transmontana olive oil (A - numbers correspond to those listed in Table 2; Group 1 - compounds n. ${ }^{\circ}$, 5, 8, 15, 21, 24, 26, 27; Group 2 - compounds n. ${ }^{\circ}$, 12-14, 16-20, 23), and from the volatile changes during storage (B - numbers correspond to those listed in Table 4; Group 3 - compounds n. $\left.{ }^{\circ} 1-4,6-13,15,16\right)$. The first two PCs explain $78.9 \%$ and $91.6 \%$ of the total variance in $\mathrm{A}$ and $\mathrm{B}$, respectively.
22.0 (IBM Corporation, New York, U.S.A.).

\section{Results and discussion}

\subsection{Effect of the extraction process on $\mathrm{cv}$. Verdeal Transmontana olive oils}

The olive oils from cv. Verdeal Transmontana reported good quality indices and could be classified as Extra-Virgin Olive Oils (EVOOs) (Commission Implementing Regulation No. 1348/2013) according to the results obtained in Table 1 .

No significant differences were found between centrifuged and clarified olive oils regarding the quality parameters nor in the antioxidant activity reported (Table 1). Other authors report limited impact of the clarification step, also known as vertical centrifugation, on the olive oils quality (Masella et al., 2009). These authors report a significant increase in PV and $\mathrm{K}_{232}$. In our study, small increases without significant differences $(P>.05)$ were also observed, with $\mathrm{PV}$ increasing from 1.3 to 1.5 meq. $\mathrm{O}_{2} \mathrm{~kg}^{-1}$, and $\mathrm{K}_{232}$ from 1.13 to 1.26 (Table 1). Regarding total phenols, from the centrifugation to the clarification step, a significant loss $(P<.001)$ of approximately $14 \%$ was observed, from 151 to $130 \mathrm{mg} \mathrm{kg}^{-1}$ (Table 1). The same trend was observed for the oxidative stability $(20.3 \mathrm{~h}$ and $18 \mathrm{~h}$ in the centrifuged and clarified olive oils, respectively; $P<.001$; Table 1 ). During the clarification stage, the added water extracts phenolic compounds from the hydrophilic phase of the oil (Masella et al., 2009), a fact corroborated by our results. The loss of oxidative stability could be related to the loss of phenolic compounds, since they are responsible for $30 \%$ of the oxidative stability of olive oils (Aparicio, Roda, Albi, \& Gutiérrez,
1999). The main phenolic compounds dissolved in the washing water (hydroxytyrosol, tyrosol, 3,4-DHPEA-EDA [dialdehydic form of decarboxymethyl elenolic acid linked to hydroxytyrosol] and other secoiridoids and derivatives from oleuropein and ligstroside (Artajo, Romero, Suárez, \& Motilva, 2007; García et al., 2001) demonstrate a high antioxidant potential (Owen et al., 2000), therefore, the oxidative stability is permanently affected. The main changes in the oils were related to the phenolic content and oxidative stability, but variations were also detected in the volatile fraction during the entire extraction process as detailed below.

The volatile composition was determined in the entire extraction process, i.e. incrushing, malaxation, centrifugation, and clarification. Thirty volatiles were identified during the extraction process of $\mathrm{cv}$. Verdeal Transmontana olive oil, namely: 13 volatiles in the fruits; 14 volatiles in the crushed olive paste; 12 volatiles in the malaxation step; 16 volatiles in the centrifuged and clarified olive oils (Table 2). Fruits were poor in volatiles, mainly composed of aldehydes, alkanes and terpenes (Table 2). The main volatile compounds present in fruits, expressed in equivalents of the internal standard, were undecane $\left(0.008 \mathrm{mg} \mathrm{kg}^{-1}\right)$, followed by D-limonene $\left(0.007 \mathrm{mg} \mathrm{kg}^{-1}\right)$, and heptanal $\left(0.004 \mathrm{mg} \mathrm{kg}^{-1}\right)$. Heptanal was exclusively present in the fruits, being absent in the following extraction steps, while D-limonene remained in the crushed paste but then disappeared from the volatile profile of the olive oils obtained (Table 2). Undecane remained in the volatile profile until the centrifugation of the olive oil $\left(0.04 \mathrm{mg} \mathrm{kg}^{-1}\right)$, but was absent once the olive oil was cleaned (Table 2).

The volatile diversity and amounts increased radically with crushing, as also highlighted by Morales and Aparicio (1999), with 
Table 3

Sensory analysis of $\mathrm{cv}$. Verdeal Transmontana olive oils (mean \pm standard deviation) at 6 and 12 months after extraction $\left(\mathrm{T}_{6}\right.$ and $\left.\mathrm{T}_{12}\right)$.

\begin{tabular}{llll}
\hline Parameter & $\mathrm{T}_{6}$ & $\mathrm{~T}_{12}$ & $P$-value \\
\hline Olfactory sensations & & & \\
Fruitiness & $5.6 \pm 0.4 \mathrm{a}$ & $5.4 \pm 0.3 \mathrm{a}$ & $.268^{(1)}$ \\
Other fruits & $1.4 \pm 0.2 \mathrm{a}$ & $1.5 \pm 0.0 \mathrm{a}$ & $.151^{(2)}$ \\
Green & $1.1 \pm 0.2 \mathrm{a}$ & $1.0 \pm 0.0 \mathrm{a}$ & $.151^{(2)}$ \\
Other sensations & $1.5 \pm 0.2 \mathrm{a}$ & $1.5 \pm 0.0 \mathrm{a}$ & $.331^{(2)}$ \\
Harmony & $17.1 \pm 0.3 \mathrm{a}$ & $17.7 \pm 0.3 \mathrm{~b}$ & $<.001^{(1)}$ \\
$\Sigma$ of olfactory sensations & $26.6 \pm 0.6 \mathrm{a}$ & $27.0 \pm 0.4 \mathrm{a}$ & $.078^{(1)}$ \\
Gustatory-olfactory sensations & & & \\
Fruitiness & $7.1 \pm 0.2 \mathrm{a}$ & $6.9 \pm 0.3 \mathrm{a}$ & $.196^{(1)}$ \\
Sweet & $3.1 \pm 0.3 \mathrm{a}$ & $3.5 \pm 0.0 \mathrm{~b}$ & $.001^{(2)}$ \\
Bitter & $2.1 \pm 0.4 \mathrm{~b}$ & $1.0 \pm 0.0 \mathrm{a}$ & $<.001^{(2)}$ \\
Pungent & $2.6 \pm 0.3 \mathrm{~b}$ & $1.7 \pm 0.2 \mathrm{a}$ & $<.001^{(1)}$ \\
Green & 1.5 & 1.0 & - \\
Other sensations & 1.5 & 1.5 & - \\
Harmony & $16.4 \pm 0.5 \mathrm{a}$ & $17.6 \pm 0.4 \mathrm{~b}$ & $<.001^{(1)}$ \\
$\Sigma$ of gustatory-olfactory sensations & $34.2 \pm 0.7 \mathrm{~b}$ & $33.1 \pm 0.5 \mathrm{a}$ & $.001^{(1)}$ \\
Olfactory-gustatory sensations & & & \\
Complexity & $7.1 \pm 0.2 \mathrm{a}$ & $7.0 \pm 0.2 \mathrm{a}$ & $.331^{(1)}$ \\
Persistence & $8.5 \pm 0.6 \mathrm{~b}$ & $7.3 \pm 0.3 \mathrm{a}$ & $<.001^{(2)}$ \\
$\Sigma$ of olfactory-gustatory sensations & $15.6 \pm 0.6 \mathrm{~b}$ & $14.3 \pm 0.4 \mathrm{a}$ & $<.001^{(1)}$ \\
Final score & $76.3 \pm 1.3 \mathrm{~b}$ & $74.4 \pm 0.7 \mathrm{a}$ & $0.001^{(1)}$ \\
& & &
\end{tabular}

${ }^{\mathrm{a}-\mathrm{b}}$ In the same line mean values with different letters differ significantly $(P<.05)$.

${ }^{1} P>.05$, by means of Levene test. $P$ values are those from one-way ANOVA analysis. Means were compared by Tukey's test, since equal variances could be assumed.

${ }^{2} P<.05$, by means of Levene test. $P$ values are those from one-way Welch ANOVA analysis. Means were compared by Dunnett T3's test.

several new compounds formed, namely aldehydes and alcohols, and a total volatile gain from 0.037 to $8.1 \mathrm{mg} \mathrm{kg}^{-1}$. The main volatiles in the crushed olive paste were (E)-2-hexenal $\left(6.95 \mathrm{mg}^{-1}\right)$, hexanal $\left(0.63 \mathrm{mg} \mathrm{kg}^{-1}\right)$, and 1 -hexanol $\left(0.35 \mathrm{mg} \mathrm{kg}^{-1}\right)$ (Table 2). The cell disruption during crushing enables a direct contact between the olives components and enzymes from the "lipoxygenase pathway", or "LOX pathway", responsible for the formation of the 'green leaf volatiles' GLVs. Several enzymes present in the pulp and stone are responsible for the oxidation (lipoxygenases) and cleavage (hydroperoxide lyases) of fatty acids (Servili et al., 2007), particularly polyunsaturated fatty acids (linoleic and linolenic), yielding the formation of hydroperoxydes and aldehydes as well as of several other volatile compounds. Therefore, the presence of $(E)$-2-hexenal and hexanal in high amounts is expected in the crushed olive paste. These two aldehydes are formed from different fatty acids, with hexanal derived from linoleic acid oxidation while $(E)$ 2 hexenal is derived from linolenic acid oxidation, by enzymatic conversion of ( $Z$ )-3-hexenal by an isomerase (cis-3:trans-2-enal isomerase). The aldehydes formed are then reduced into alcohols. Hexanal yields 1hexanol while ( $Z$ )-3-hexenal yields $(Z)$-3-hexen-1-ol, both by the action of an alcohol dehydrogenase (Kalua et al., 2007). Therefore, the main alcohols present in the olive pastes were (Z)-3-hexen-1-ol (0.02 $\mathrm{mg} \mathrm{kg}^{-1}$ ) and 1-hexanol $\left(0.35 \mathrm{mg} \mathrm{kg}^{-1}\right)$.

Once the olives were crushed and the olive paste was formed, the material was malaxed during $1 \mathrm{~h}$ at $27^{\circ} \mathrm{C}$. The volatile profile was quite similar between crushed and malaxed olive pastes, both qualitative and quantitatively (Table 2). Only phenylethyl alcohol and D-limonene went below the detection limit from crushed to malaxed olive pastes, while all the remaining compounds reported similar amounts (no significant differences for all the volatiles identified $P>.05$; Table 2). Malaxation is described to influence the development of flavor compounds by the LOX pathway by favoring the enzymatic contact and air incorporation. It is known to influence the development of the GLVs, as reported by Servili, Selvaggini, Taticchi, Esposto, and Montedoro (2003). However, this potential enhancement of GLVs was not immediately visible here. Also, malaxation at low temperatures $\left(27^{\circ} \mathrm{C}\right)$ and time $(1 \mathrm{~h})$, following standard quality protocols, did not induce an increase in the volatile oxidation markers of the oil.

After malaxation, the volatile fraction from the centrifuged olive oil was mainly composed of aldehydes, with a 10 -fold enrichment in comparison with the previous step $\left(76.8 \mathrm{mg} \mathrm{kg}^{-1}\right.$ ) (Table 2). The main compounds were again (E)-2-hexenal $\left(65.5 \mathrm{mg} \mathrm{kg}^{-1}\right)$, hexanal $\left(5.84 \mathrm{mg} \mathrm{kg}^{-1}\right)$, 1-hexanol $\left(2.29 \mathrm{mg} \mathrm{kg}^{-1}\right)$, while $(Z)$-3-hexenyl acetate was detected for the first time $\left(1.08 \mathrm{mg} \mathrm{kg}^{-1}\right)$. Also, increases were detected in the sesquiterpene fraction and hydrocarbons $(0.94 \mathrm{mg} / \mathrm{kg})$.

After centrifugation in the decanter, the olive must was then clarified in a vertical centrifuge, where a marked concentration of volatiles was verified, with an increase of up to $130 \mathrm{mg} \mathrm{kg}^{-1}$ (Table 2). The main volatiles were enhanced, for instance $(E)$-2-hexenal increased $68 \%$, hexanal increased 43\%, 1-hexanol doubled its amounts, and (Z)-3hexenyl acetate quadrupled its presence in the olive oil (Table 2). However, an increase in markers of the oxidative process was also noticed, namely nonanal (Cavalli, Fernandez, Lizzani-Cuvelier, \& Loiseau, 2004; Vichi, Pizzale, Conte, Buxaderas, \& Lopez-Tamames, 2003) and (E)-2-decenal (Jiménez, Beltrán, \& Aguilera, 2004; Kanavouras, Hernandez-Munoz, Coutelieris, \& Selke, 2004). Nonanal increased from 0.06 to $0.51 \mathrm{mg} \mathrm{kg}^{-1}(P<.001)$ and $(E)$-2-decenal was reported for the first time. The vertical centrifugation caused a slight oxidation of the oil, due to the formation of hydroperoxydes and conjugated dienes (increase in PV and $\mathrm{K}_{232}$ respectively; Table 1). This oxidation could be attributed to the incorporation of oxygen in the oil. According to Masella et al. (2009), vertical centrifugation introduces 4.5 times more dissolved oxygen in the oil, an aspect that will favor the autoxidation process during storage. Enzymatic oxidation is a dynamic process and therefore, the time taken between crushing/malaxation and further processing steps will define the extent of the reactions taking place derived from the contact of the enzymes with the oil. Also, the final elimination of water in the clarification can cause a more effective removal of residual enzymes and refrain their action from this step forward.

The volatile profile obtained during the extraction process of olive oils from cv. Verdeal Transmontana allowed separating the extraction steps (Fig. 1A). Olives were characterized by their exclusive volatiles and D-limonene. Crushing and malaxation steps were difficult to separate since the volatile profile obtained was quite similar (Fig. 1A and Table 2). The centrifugation step was characterized by a higher concentration of $(E, E)$-2,4-hexadienal (4) and the isomers of 3-ethyl-1,5octadiene (28 and 29). The most distinguishable step was the clarification, after which the olive oil was characterized by the main GLVs, such as hexanal (1), (E)-2-hexenal (2), 1-hexanol (11), and (Z)-3-hexenyl acetate (13) (Fig. 1A and Table 2).

\subsection{Effect of storage on $\mathrm{cv}$. Verdeal Transmontana olive oil}

The olive oil from cv. Verdeal Transmontana continued to present good quality indices 12 months after extraction $\left(\mathrm{T}_{12}\right)$, and could be classified as EVOO (Table 1; FA $\leq 0.8 \%$; PV $\leq 20$ meq. $\mathrm{O}_{2} \mathrm{~kg}^{-1}$; $\mathrm{K}_{232} \leq 2.50 ; \mathrm{K}_{270} \leq 0.22 ; \Delta \mathrm{K} \leq 0.01$ ). Nevertheless, 12 months after extraction, the oils were oxidized, their antioxidant properties were reduced, their chemical composition (phenols and volatiles) and sensory attributes had changed. Only FA kept unchanged, with $0.3 \%$. Peroxide value increased from 1.5 to 9.2 meq. $\mathrm{O}_{2} \mathrm{~kg}^{-1}$, in clarified $\left(\mathrm{T}_{0}\right)$ and $\mathrm{T}_{12}$, respectively. Therefore, primary oxidation occurred, also observed by the formation of conjugated dienes, as $\mathrm{K}_{232}$ increased from 1.26 to 2.17 in $T_{0}$ and $T_{12}$, respectively (Table 1 ). However, oxidation was not extensive since no formation of secondary compounds of oxidation occurred (reduced $\mathrm{K}_{270}$ values in the olive oils; Table 1).

Regarding sensory analysis, the clarified olive oil was assessed 6 and 12 months after extraction $\left(\mathrm{T}_{6}\right.$ and $\mathrm{T}_{12}$ ). Indeed, recently extracted olive oils have strong scents that mask some attributes, and it is generally recommended that the first sensory evaluation be performed after reaching a sensory equilibrium, since some attributes present may be masked. In the olfactory sensations, significant differences in 'harmony' 
Table 4

Changes in volatile compounds of cv. Verdeal Transmontana olive oils within one year after extraction (mg kg-1 of olive oil)*.

\begin{tabular}{|c|c|c|c|c|c|c|c|c|c|c|}
\hline \multicolumn{2}{|c|}{ Compound } & $\mathrm{LRI}^{\mathrm{A}}$ & LRI Lit ${ }^{\mathrm{B}}$ & $\mathrm{QI}^{\mathrm{C}}$ & $\mathrm{ID}^{\mathrm{D}}$ & $\mathrm{T}_{0}$ & $\mathrm{~T}_{4}$ & $\mathrm{~T}_{8}$ & $\mathrm{~T}_{12}$ & $P$-value \\
\hline \multicolumn{11}{|c|}{ Aldehydes } \\
\hline 1 & Hexanal & 797 & 801 & 44 & S/MS & $8.37 \pm 0.56 \mathrm{~d}$ & $5.67 \pm 0.16 \mathrm{c}$ & $0.78 \pm 0.04 \mathrm{~b}$ & $0.40 \pm 0.05 \mathrm{a}$ & $<.001^{(1)}$ \\
\hline 2 & (E)-2-hexenal & 855 & 855 & 41 & S/MS & $110 \pm 5.01 \mathrm{~d}$ & $91.4 \pm 2.72 \mathrm{c}$ & $13.2 \pm 0.89 \mathrm{~b}$ & $7.07 \pm 0.36 \mathrm{a}$ & $<.001^{(1)}$ \\
\hline 3 & Nonanal & 1098 & 1100 & 41 & S/MS & $0.51 \pm 0.05 \mathrm{~b}$ & $0.60 \pm 0.17 b$ & $0.06 \pm 0.05 \mathrm{a}$ & $0.02 \pm 0.01 \mathrm{a}$ & $<.001^{(1)}$ \\
\hline 4 & (E)-2-decenal & 1258 & 1263 & 43 & S/MS & $0.17 \pm 0.05 \mathrm{a}$ & $0.19 \pm 0.09 \mathrm{a}$ & - & - & $.521^{(2)}$ \\
\hline \multicolumn{2}{|c|}{$\Sigma$ aldehydes } & & & & & $119 \pm 5.3 \mathrm{~d}$ & $97.8 \pm 2.65 c$ & $14.0 \pm 0.89 \mathrm{~b}$ & $7.50 \pm 0.41 \mathrm{a}$ & $P<.001^{(1)}$ \\
\hline \multicolumn{11}{|c|}{ Alcohols } \\
\hline 5 & (Z)-3-hexen-1-ol & 860 & 859 & 67 & S/MS & $0.19 \pm 0.06 \mathrm{~b}$ & $0.29 \pm 0.12 b$ & $0.04 \pm 0.03 \mathrm{a}$ & $0.03 \pm 0.01 \mathrm{a}$ & $<.001^{(1)}$ \\
\hline 6 & 1-Hexanol & 871 & 870 & 56 & S/MS & $4.42 \pm 0.64 \mathrm{c}$ & $3.90 \pm 0.59 \mathrm{c}$ & $0.83 \pm 0.15 \mathrm{~b}$ & $0.36 \pm 0.07 \mathrm{a}$ & $<.001^{(1)}$ \\
\hline 7 & Phenylethyl alcohol & 1108 & 1107 & 91 & MS & $0.16 \pm 0.03 \mathrm{~b}$ & $0.15 \pm 0.02 b$ & - & $0.004 \pm 0.002 \mathrm{a}$ & $<.001^{(1)}$ \\
\hline \multicolumn{2}{|c|}{$\Sigma$ alcohols } & & & & & $4.77 \pm 0.70 \mathrm{~b}$ & $4.34 \pm 0.70 \mathrm{~b}$ & $0.87 \pm 0.17 \mathrm{~b}$ & $0.40 \pm 0.08 \mathrm{a}$ & $<.001^{(1)}$ \\
\hline \multicolumn{11}{|c|}{ Esters } \\
\hline 8 & (Z)-3-hexenyl acetate & 1007 & 1005 & 43 & S/MS & $4.26 \pm 0.38 \mathrm{c}$ & $3.92 \pm 0.57 \mathrm{c}$ & $0.49 \pm 0.04 \mathrm{~b}$ & $0.22 \pm 0.06 \mathrm{a}$ & $<.001^{(1)}$ \\
\hline 9 & Hexyl acetate & 1012 & 1009 & 43 & S/MS & $0.32 \pm 0.04 \mathrm{a}$ & $0.37 \pm 0.08 \mathrm{a}$ & - & - & $.074^{(2)}$ \\
\hline \multicolumn{2}{|c|}{$\Sigma$ esters } & & & & & $4.58 \pm 0.41 \mathrm{c}$ & $4.28 \pm 0.58 c$ & $0.49 \pm 0.04 \mathrm{~b}$ & $0.22 \pm 0.06 \mathrm{a}$ & $P<.001^{(1)}$ \\
\hline \multicolumn{11}{|c|}{ Sesquiterpenes } \\
\hline 10 & $\alpha$-Cubebene & 1356 & 1358 & 161 & MS & $0.17 \pm 0.03 \mathrm{~d}$ & $0.12 \pm 0.03 c$ & $0.01 \pm 0.00 \mathrm{~b}$ & $0.004 \pm 0.001 \mathrm{a}$ & $<.001^{(1)}$ \\
\hline 11 & Copaene & 1373 & 1376 & 161 & MS & $0.55 \pm 0.11 \mathrm{~b}$ & $0.38 \pm 0.05 \mathrm{~b}$ & $0.03 \pm 0.00 \mathrm{a}$ & $0.01 \pm 0.00 \mathrm{a}$ & $<.001^{(1)}$ \\
\hline 12 & (E)- $\alpha$-bergamotene & 1432 & 1434 & 119 & MS & $0.14 \pm 0.02 \mathrm{~d}$ & $0.08 \pm 0.03 c$ & $0.01 \pm 0.01 \mathrm{~b}$ & $0.002 \pm 0.001 \mathrm{a}$ & $<.001^{(1)}$ \\
\hline 13 & $(E, E)$ - $\alpha$-farnesene & 1504 & 1505 & 41 & MS & $0.33 \pm 0.08 \mathrm{~b}$ & $0.22 \pm 0.06 \mathrm{a}$ & - & - & $.003^{(2)}$ \\
\hline 14 & $\delta$-Cadinene & 1517 & 1523 & 161 & MS & $0.09 \pm 0.01$ & - & - & - & - \\
\hline \multicolumn{2}{|c|}{$\Sigma$ sesquiterpenes } & & & & & $1.28 \pm 0.19 \mathrm{~d}$ & $0.80 \pm 0.15 c$ & $0.05 \pm 0.01 \mathrm{~b}$ & $0.02 \pm 0.01 \mathrm{a}$ & $<.001^{(1)}$ \\
\hline \multicolumn{11}{|c|}{ Terpenes } \\
\hline & $(E)$ - $\beta$-ocimene & 1051 & 1050 & 93 & MS & $0.29 \pm 0.03 c$ & $0.26 \pm 0.01 \mathrm{c}$ & $0.02 \pm 0.00 \mathrm{~b}$ & $0.01 \pm 0.00 \mathrm{a}$ & $<.001^{(1)}$ \\
\hline \multicolumn{2}{|c|}{$\Sigma$ terpenes } & & & & & $0.29 \pm 0.03 \mathrm{c}$ & $0.26 \pm 0.01 \mathrm{c}$ & $0.02 \pm 0.00 \mathrm{~b}$ & $0.01 \pm 0.00 \mathrm{a}$ & $<.001^{(1)}$ \\
\hline \multicolumn{11}{|c|}{ Hydrocarbons } \\
\hline & 4,8-Dimethyl-1,7-nonadiene & 997 & - & 41 & MS & $0.80 \pm 0.17 \mathrm{c}$ & $0.74 \pm 0.18 \mathrm{c}$ & $0.15 \pm 0.03 \mathrm{~b}$ & $0.06 \pm 0.02 \mathrm{a}$ & $<.001^{(1)}$ \\
\hline \multicolumn{2}{|c|}{$\Sigma$ hydrocarbons } & & & & & $0.80 \pm 0.17 \mathrm{c}$ & $0.74 \pm 0.18 \mathrm{c}$ & $0.15 \pm 0.03 \mathrm{~b}$ & $0.06 \pm 0.02 \mathrm{a}$ & $<.001^{(1)}$ \\
\hline \multicolumn{11}{|c|}{ Ketones } \\
\hline 17 & 6-Methyl-5-hepten-2-one & 987 & 985 & 43 & S/MS & - & - & - & $0.01 \pm 0.00$ & - \\
\hline \multicolumn{3}{|c|}{$\Sigma$ ketones } & & & & - & - & - & $0.01 \pm 0.00$ & - \\
\hline \multicolumn{3}{|c|}{ Total volatiles } & & & & $130 \pm 5.50 \mathrm{~d}$ & $108 \pm 2.14 \mathrm{c}$ & $15.6 \pm 0.87 \mathrm{~b}$ & $8.21 \pm 0.50 \mathrm{a}$ & $<.001^{(1)}$ \\
\hline
\end{tabular}

${ }^{\mathrm{a}-\mathrm{d}}$ In the same line mean values with different letters differ significantly $(P<.05)$.

$*$ Values are from semi-quantification using 4-methyl-2-pentanol as internal standard.

${ }^{\text {A }}$ LRI - Linear retention index obtained in a TRB-5MS column.

B LRI Lit - Linear retention index reported in literature (Adams, 2007).

${ }^{\text {C }}$ Quantification ion.

${ }^{D}$ Identification method (S - identified with standard; MS - identified by comparing mass spectrum with database NIST 11).

${ }^{1} P<.05$, by means of Levene test. $P$ values are those from one-way Welch ANOVA analysis. Means were compared by Dunnett T3's test, since equal variances could not be assumed.

${ }^{2} P>.05$, by means of Levene test. $P$ values are those from one-way ANOVA analysis. Means were compared by Tukey's test.

were noticed, with $17.1\left(\mathrm{~T}_{6}\right)$ and $17.7\left(\mathrm{~T}_{12}\right)(P<.001$; Table 3$)$.

Other parameters reduced their score from $\mathrm{T}_{6}$ to $\mathrm{T}_{12}$ : 'fruitiness' from 5.6 to 5.4 , and 'green' from 1.1 to 1.0 . In the gustatory-olfactory sensations, several changes were verified. 'Fruitiness' decreased reduced from 7.1 to 6.9 ( $P=.196)$, and 'green' from 1.5 to 1.0 (Table 3). This reduction could be explained by the loss of volatile compounds detailed in Table 4.

Immediately after extraction (clarification; $\mathrm{T}_{0}$ ) the total volatiles concentration was $130 \mathrm{mg} \mathrm{kg}^{-1}$, and with storage, it dropped to $108 \mathrm{mg} \mathrm{kg}^{-1}, 15.6 \mathrm{mg} \mathrm{kg}^{-1}$, and $8.21 \mathrm{mg} \mathrm{kg}^{-1}$, at $4\left(\mathrm{~T}_{4}\right), 8\left(\mathrm{~T}_{8}\right)$ and 12 months $\left(\mathrm{T}_{12}\right)$ of storage, respectively (Table 4). The volatiles responsible for the green/grass (GLVs) and fruity attributes such as hexanal, (E)-2-hexenal, (Z)-3-hexen-1-ol, 1-hexanol, (Z)-3-hexenyl acetate were extremely affected by storage (Aparicio et al., 1996). For instance, (E)-2-hexenal, the main volatile present in olive oils, suffered a reduction of $93.5 \%$ of its concentration after $\mathrm{T}_{12}$. A similar result was verified by Kalua, Bedgood, \& Prenzler (2006) by studying the volatile profile of olive oil during a storage period of 12 months. Kalua, Bedgood, \& Prenzler (2006) reported losses around 70\%, and 64\% for (E)-2-hexenal and 1-hexanol, respectively. Furthermore, the reduction in (E)-2-hexenal content indicates a loss of freshness, since this aldehyde is a freshness marker (Kalua, Bedgood, Bishop, \& Prenzler, 2006). Hexanal and (Z)-3-hexenyl acetate were also considerably reduced from $\mathrm{T}_{0}$ to $\mathrm{T}_{12}$ (Table 4). The reduction of these GLVs, even if low between $\mathrm{T}_{6}$ (not evaluated) and $\mathrm{T}_{12}$, clearly influenced the retronasal judgment of the panelists, mainly as far as 'fruity' and 'green' attributes are concerned. 'Bitter' and 'pungent' were also significantly reduced $(P<.001)$ with storage. 'Bitter' and 'pungent' scores decreased from 2.1 to 1.0 and from 2.6 to 1.7 , respectively. These two parameters are highly dependent on the concentration of phenolic compounds (Servili et al., 2004). At $\mathrm{T}_{12}$, the olive oil lost $50 \%$ of phenolic compounds, reporting $65.2 \mathrm{mg}$ $\mathrm{CAE} \mathrm{kg}^{-1}$ (Table 1). With the loss of phenolic compounds, the olive oil lost $57 \%$ of its oxidative stability (from $18 \mathrm{~h}$ at $\mathrm{T}_{0}$ to $7.7 \mathrm{~h}$ at $\mathrm{T}_{12}$ ) and the antioxidant activity was also significantly affected $(46.1 \%$ and $37.2 \%$ at $\mathrm{T}_{0}$ and $\mathrm{T}_{12}$ respectively; $P<.001$; Table 1 ).

In contrast, as 'bitter' and 'pungent' decrease, the 'sweet' attribute increases from 3.1 to $3.5(P=.001)$. Another important result was the increase of 'harmony' from 16.4 at $\mathrm{T}_{6}$ to 17.6 at $\mathrm{T}_{12}$. Since mainly 'green', 'pungent' and 'bitter' attributes were reduced, the olive oil became more harmonious, since the major attributes did not mask others as in the first assessment at $\mathrm{T}_{6}$. Overall, and due to the losses of 'green', 'bitter', 'pungent' and in lower extent 'fruity', the sum of the gustatory-olfactory sensations showed a significant reduction $(P=.001$; Table 3$)$.

The two other parameters evaluated were 'complexity' and 'persistence', which compose the olfactory-gustatory sensations. No differences were observed in the 'complexity' $\left(7.1\right.$ and 7.0 at $\mathrm{T}_{6}$ and $\mathrm{T}_{12}$, respectively; $P=.331$; Table 3 ). The 'persistence', highly correlated 


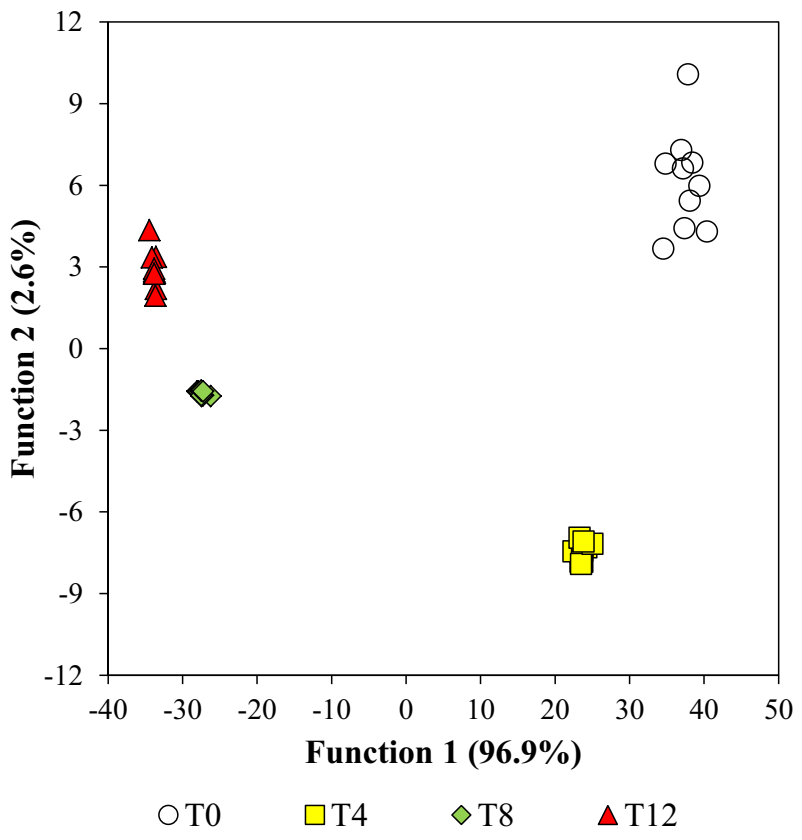

Fig. 2. Linear discriminant analysis of the cv. Verdeal Transmontana olive oils stored over one year $\left(\mathrm{T}_{0}-\right.$ clarified oil; $\mathrm{T}_{4}-4$ months of storage; $\mathrm{T}_{8}-8$ months of storage; $\mathrm{T}_{12}-12$ months of storage). The two discriminant functions explain $98.5 \%$ of the total variance.

with 'pungent', was significantly reduced from 8.5 to $7.3(P<.001)$. This result may be related to the loss of phenolic compounds during storage (Table 1). The final score of the olive oil was significantly reduced $(P=.001)$. Nevertheless, the panelists consider the oils as EVOOs, since no defects were detected.

The changes observed in the volatile profile of the olive oils during storage allowed their differentiation (Fig. 1B). The oils from $\mathrm{T}_{0}$ and $\mathrm{T}_{4}$ were completely different from those at $\mathrm{T}_{8}$ and $\mathrm{T}_{12}$, being the latter two more similar between each other. This stabilization is also in accordance with the stabilization period recommended for sensory analysis. Oils at $\mathrm{T}_{0}$ and $\mathrm{T}_{4}$ were characterized by the highest amounts of GLVs but also many other compounds present in Group 3 (Fig. 1B, compounds listed in Table 4). Olive oils from $\mathrm{T}_{0}$ were specifically characterized by the presence of $\delta$-cadinene (14), while oils from $\mathrm{T}_{4}$ were characterized by higher amounts of (Z)-3-hexen-1-ol (5). The oils from $T_{8}$ and $T_{12}$ were characterized by lower contents of most of the volatiles identified. Nevertheless, $\mathrm{T}_{12}$ was also characterized by the exclusive presence of the ketone 6-methyl-5-hepten-2-one (17) (Fig. 1B and Table 4).

An LDA was also applied to the data obtained in the volatile profile of the olive oils from cv. Verdeal Transmontana stored. The LDA resulted in a discriminate model with three significant discriminant functions that explained $100 \%$ of the variance, the first two explaining 98.5\% of the variance of the experimental data (Fig. 2).

From the 17 variables/volatiles identified, only six were considered as discriminant variables, namely $(E)$-2-hexenal (2), $\delta$-cadinene (14), 6methyl-5-hepten-2-one (17), 1-hexanol (6), copaene (11), and (E,E)- $\alpha$ farnesene (13). The model showed a very satisfactory classification performance allowing the correct classification of all the samples for the original groups as well as for the cross-validation procedure (sensitivities and sensibilities of $100 \%$ ). It would be possible to estimate the storage duration of the olive oil using its volatile profile, settled for the conditions used in this study. Nevertheless, several other variables need to be taken into account, like the cultivar, the maturation degree, the extraction process, among other characteristics, extending this study to further samples and conditions. Furthermore, in order to validate the model, the samples need to be extracted and stored under the same conditions.

\section{Conclusions}

The present work allowed concluding that the extraction process causes changes in the volatile profile of cv. Verdeal Transmontana olive oils. Main changes are observed during crushing and malaxation steps, where GLVs are formed. The final step, the clarification, allowed an increase in the contents of the main volatiles present in the oils. It would be interesting to study this step to increase the amount of green/ fruity/fresh aromas in the olive oils without significantly increasing offflavors. Nevertheless, we also concluded that clarification reduces the amounts of antioxidants and therefore the oxidative stability of the olive oils obtained, mainly due to the removal of antioxidants during the washing of the oil with small amounts of water.

Another conclusion drawn from the study was that after 12 months the olive oil lost a considerable part of volatiles, phenols, antioxidant potential, resistance to oxidation, and the 'bitter', 'pungent', 'green' and 'persistence' sensory attributes were reduced, thus increasing the attributes 'harmony' and 'sweet'. In order for the volatiles and positive sensory attributes of the oil to be preserved, it should be consumed as soon as possible, within the first 4-6 months after extraction.

The study of the volatile profile of the extraction steps and the olive oil storage allowed distinguishing and discriminating the several samples studied, showing that the volatile profile is unique at each point of the extraction process and during storage, and that it can be used as a discriminating tool.

\section{Acknowledgements}

Ricardo Malheiro thanks FCT, POPH-QREN and FSE for the PostDoctoral grant (SFRH/BPD/111901/2015). The authors thank the Casa Santo Amaro and their owners for the samples availability and the kindness for allowing the use of their facilities to extract the oils.

\section{References}

Adams, R. P. (2007). Identification of essential oil components by gas chromatography/mass spectrometry (4th ed.). Carol Stream: Allured Publishing Corporation.

Angerosa, F., Mostallino, R., Basti, C., \& Vito, R. (2001). Influence of malaxation temperature and time on the quality of virgin olive oils. Food Chemistry, 72, 19-28.

Aparicio, R., Morales, M. T., \& Alonso, M. V. (1996). Relationship between volatile compounds and sensory attributes of olive oils by the sensory wheel. Journal of the American Oil Chemists' Society, 73, 1253-1264.

Aparicio, R., Roda, L., Albi, M. A., \& Gutiérrez, F. (1999). Effect of various compounds on virgin olive oil stability measured by Rancimat. Journal of Agricultural and Food Chemistry, 47, 4150-4155.

Artajo, L.-S., Romero, M.-P., Suárez, M., \& Motilva, M.-J. (2007). Partition of phenolic compounds during the virgin olive oil industrial extraction process. European Food Research and Technology, 225, 617-625.

Caponio, F., Summo, C., Paradiso, V. M., \& Pasqualone, A. (2014). Influence of decanter working parameters on the extra virgin olive oil quality. European Journal of Lipid Science and Technology, 116, 1626-1633.

Caporaso, N. (2016). Virgin olive oils: Environmental conditions, agronomical factors and processing technology affecting the chemistry of flavor profile. Journal of Food Chemistry and Nanotechnology, 2, 21-31.

Cavalli, J.-F., Fernandez, X., Lizzani-Cuvelier, L., \& Loiseau, A. M. (2004). Characterization of volatile compounds of French and Spanish virgin olive oils by HSSPME: Identification of quality-freshness markers. Food Chemistry, 88, 151-157.

Commission Implementing Regulation No. 1348/2013 Amending Regulation (ECC) No. $2568 / 91$ on the characteristics of olive oil and olive-residue oil and on the relevant methods of analysis. Official Journal of the European Union, L.838/31-L.838/67.

García, A., Brenes, M., Martínez, F., Alba, J., García, P., \& Garrido, A. (2001). Highperformance liquid chromatography evaluation of phenols in virgin olive oil during extraction of laboratory and insdustrial scale. Journal of the American Oil Chemists' Society, 78, 625-629.

Genovese, A., Caporaso, N., \& Sacchi, R. (2015). Temporal changes of virgin olive oil volatile compounds in a model system simulating domestic consumption: The role of biophenols. Food Research International, 77, 670-674.

Gómez-Rico, A., Inarejos-García, A. M., Salvador, M. D., \& Fregapane, G. (2009). Effect of malaxation conditions on phenol and volatile profiles in olive paste and the corresponding virgin olive oils (Olea europaea L. Cv. Cornicabra). Journal of Agricultural and Food Chemistry, 57, 3587-3595.

Hermoso, M., Uceda, M., García, A., Morales, B., Frias, M. L., \& Fernández, A. (1991). 
Elaboración de Aceite de Calidad. Sevilla: Consejeria de Agricultura y Pesca.

International Olive Council. IOC Mario Solinas quality award - Rules of the international competition for extra virgin olive oils. COI/T.30/Doc. No. 17 June 2014. (2014). http:// www.internationaloliveoil.org/ (Accessed 16 August 2016).

Jiménez, A., Beltrán, G., \& Aguilera, M. P. (2004). Application of solid-phase microextraction to the analysis of volatile compounds in virgin olive oils. Journal of Chromatography A, 1028, 321-324.

Kalua, C. M., Allen, M. S., Bedgood, D. R., \& Bishop, A. G. (2005). Discrimination of olive oils and fruits into cultivars and maturity stages based on phenolic and volatile compounds. Journal of Agricultural and Food Chemistry, 53, 8054-8062.

Kalua, C. M., Allen, M. S., Bedgood, D. R., Bishop, A. G., Prenzler, P. D., \& Robards, K. (2007). Olive oil volatile compounds, flavor development and quality: A critical review. Food Chemistry, 100, 273-286.

Kalua, C. M., Bedgood, D. R., Bishop, A. G., \& Prenzler, P. D. (2006). Discrimination of storage conditions and freshness in virgin olive oil. Journal of Agricultural and Food Chemistry, 54, 7144-7151.

Kalua, C. M., Bedgood, D. R., \& Prenzler, P. D. (2006). Development of a headspace solid phase microextraction-gas chromatography method for monitoring volatile compounds in extended time-course experiments of olive oil. Analytica Chimica Acta, 556, 407-414.

Kanavouras, A., Hernandez-Munoz, P., Coutelieris, F., \& Selke, S. (2004). Oxidation-derived flavor compounds as quality indicators for packaged olive oil. Journal of the American Oil Chemists' Society, 81, 251-247.

Malheiro, R., Casal, S., Baptista, P., \& Pereira, J. A. (2015). A review of Bactrocera oleae (Rossi) impact in olive products: From the tree to the table. Trends in Food Science and Technology, 44, 226-242.

Malheiro, R., Rodrigues, N., Bissaro, C., Leimann, F., Casal, S., Ramalhosa, E., \& Pereira, J. A. (2017). Improvement of sensorial and volatile profiles of olive oil by addition of olive leaves. European Journal of Lipid Science and Technology, 119, 1700177.

Masella, P., Parenti, A., Spugnoli, P., \& Calamai, L. (2009). Influence of vertical centrifugation on extra virgin olive oil quality. Journal of the American Oil Chemists Society, 86, 1137-1140.

Masella, P., Parenti, A., Spugnoli, P., \& Calamai, L. (2012). Vertical centrifugation of virgin olive oil under inert gas. European Journal of Lipid Science and Technology, 114, 1094-1096.

Morales, M. T., \& Aparicio, R. (1999). Effect of extraction conditions on sensory quality of virgin olive oil. Journal of the American Oil Chemists' Society, 76, 295-300.

Owen, R. W., Giacosa, A., Hull, W. E., Haubner, R., Spiegelhalder, B., \& Bartsch, H. (2000). The antioxidant/anticancer potential of phenolic compounds isolated from olive oil. European Journal of Cancer, 36, 1235-1247.
Peres, F., Jelen, H. H., Majcher, M. M., Arraias, M., MArtins, L. L., \& Ferreira-Dias, S. (2013). Characterization of aroma compounds in Portuguese extra virgin olive oils from Galega vulgar and Cobrançosa cultivars using GC-O and GC $\times$ GC-ToFMS. Food Research International, 54, 1979-1986.

Ranalli, A., Cabras, P., Iannucci, E., \& Contento, S. (2001). Lipochromes, vitamins, aromas and other components of virgin olive oil are affected by processing technology. Food Chemistry, 73, 445-451.

Ridolfi, M., Terenziani, S., Patumi, M., \& Fontanazza, G. (2002). Characterization of the lipoxygenases in some olive cultivars and determination of their role in volatile compounds formation. Journal of Agricultural and Food Chemistry, 50, 835-839.

Sacchi, R., Caporaso, N., Paduano, A., \& Genovese, A. (2015). Industrial-scale filtration affects volatile compounds in extra virgin olive oil cv. Ravece. European Journal of Lipid Science and Technology, 117, 2007-2014.

Servili, M., Selvaggini, R., Esposto, S., Taticchi, A., Montedoro, G., \& Morozzi, G. (2004). Health and sensory properties of virgin olive oil hydrophilic phenols: Agronomic and technological aspects of production that affect their occurrence in the oil. Journal of Chromatography A, 1054, 113-127.

Servili, M., Selvaggini, R., Taticchi, A., Esposto, S., \& Montedoro, G. (2003). Air exposure time of olive pastes during the extraction process and phenolic and volatile composition of virgin olive oil. Journal of Agricultural and Food Chemistry, 80, 685-695.

Servili, M., Taticchi, A., Esposto, S., Urbani, S., Selvaggini, R., \& Montedoro, G. (2007). Effect of olive stoning on the volatile and phenolic composition of virgin olive oil. Journal of Agricultural and Food Chemistry, 55, 7028-7035.

Servili, M., Taticchi, A., Esposto, S., Urbani, S., Selvaggini, R., \& Montedoro, G. (2008). Influence of the decrease in oxygen during malaxation of olive paste on the composition of volatiles and phenolic compounds in virgin olive oil. Journal of Agricultural and Food Chemistry, 56, 10048-10055.

Sousa, A., Casal, S., Malheiro, R., Lamas, H., Bento, A., \& Pereira, J. A. (2015). Aromatized olive oils: Influence of flavouring in quality, composition, stability, antioxidants, and antiradical potential. LWT-Food Science and Technology, 60, 22-28.

Veillet, S., Tomao, V., Bornard, I., Ruiz, K., \& Chemat, F. (2009). Chemical changes in virgin olive oils as a function of crushing systems: Stone mill and hammer crusher. Comptes Rendus Chimie, 12, 895-904.

Vichi, S., Pizzale, L., Conte, L. S., Buxaderas, S., \& Lopez-Tamames, E. (2003). Solid-phase microextraction in the analysis of virgin olive oil volatile fraction: Modifications induced by oxidation and suitable markers of oxidative status. Journal of Agricultural and Food Chemistry, 51, 6564-6571.

Youssef, O., Guido, F., Manel, I., Youssef, N. B., Luigi, C. P., Mohamed, H., ... Mokhtar, Z. (2011). Volatile compounds and compositional quality of virgin olive oil from Oueslati variety: Influence of geographical origin. Food Chemistry, 124, 1770-1776. 